\title{
Study on Exergy Recovery in Hybrid Vehicles via Wastegate Losses
}

\author{
A. J. T. B. de Lima ${ }^{1 *}$, C. H. Rufino ${ }^{2}$, J. V. Ferreira ${ }^{3}$, W. L. R. Gallo ${ }^{4}$ \\ 123 4University of Campinas, Cidade Universitária “Zeferino Vaz”, Faculty of Mechanical Engineering, 13093-970, \\ Campinas, Brazil \\ alessandrojtblima@gmail.com,
}

Received 15 October 2019, Revised 2 February 2020, Accepted 11 February 2020

\begin{abstract}
Vehicle hybridization is considered a promising alternative for pollutant emission mitigation. This type of vehicle combines the use of an internal combustion engine and electrical power. One of the most common layouts is the series-parallel hybrid vehicle, which consists of using a combustion engine as the main source of power in parallel to electrical sources. Besides propelling the vehicle, the combustion engine has the task of supplying energy to the electrical system. In parallel to hybridization, other technologies such as engine downsizing via turbocharging have been adopted to increase thermal efficiency of internal combustion engines. The purpose of this work is to analyze the viability of combining aforementioned technologies. To improve energy utilization, part of the exhaust system energy is recovered from a free turbine connected to the vehicle's battery. To evaluate the proposal viability, experimental data was obtained from a turbocharged spark-ignition engine. Efficiency indexes were calculated based on exergetic analyses for the turbocompressor set and the entire engine system. Thereafter, a virtual free turbine was added, assuming that it operates exactly as the main turbine and the efficiency indexes were recalculated as absolute values of recovered energy. The free turbine recovers up to $1.2 \%$ of fuel exergy and increases power by almost $5.2 \%$ at full load conditions.
\end{abstract}

Keywords: Hybrid vehicles; gasohol; exergetic efficiency; downsizing; spark-ignition engines.

\section{Introduction}

Environmental issues are leading to an intensive search for energetic efficiency improvement for vehicles. Hybrid electrical vehicles (HEV) are a strong alternative for efficiency improvement as they combine different propulsion systems, in addition to offer the possibility of recovering different forms of energy to the electrical system [1], [2], [3]. Another alternative currently implemented is the downsizing of internal combustion engines. This strategy consists in adopting turbocharged engines with lower cubic capacities that can deliver higher amounts of power with the advantages of less weight and volume. Turbocharging allows recovering available exergy flow of the exhaust gases and transfer part of this available work to pump air to engine cylinders, hence obtaining more power and higher efficiency. However, this operational state is only obtained during high load conditions. Most of the operation of the engine occurs on part load state and part of the exhaust gases are expelled via a wastegate valve.

Energy recovery from turbocharging systems comprises a wide variety of technologies recently used to increase efficiency of different types of powertrain systems. Researches evaluate the implementation of such technology not only on hybrid electric vehicles [4], but also in combustion vehicles [5], [6]. Electric Turbo Compound (ETC) is a recent strategy for recovering energy lost through exhaust system. Pioneer research on the ground was carried out for increasing efficiency of heavy-duty engines. Hoppmann and Algrain [7] presented the development and simulation of an ETC, in which the generator was directly coupled to the turbine of a heavyduty diesel engine. An improvement of 5\% to $10 \%$ was obtained for fuel consumption. A more recent work [8] executed a simulation, predicting the performance of an ETC system on a small aspirated diesel engine with the objective of generating power to auxiliary systems of the vehicle. The results provided 6 to $9 \%$ of fuel consumption savings. Experimental investigations were also executed for spark-ignition engines. Mamat et. al. [9] tested the implementation of a low-pressure turbine coupled downstream from the main turbine of a turbocharged gasoline engine. This configuration indicated a reduction of $2.6 \%$ for maximum Break Specific Fuel Consumption (BSFC). Zhuge et. al. [10] pointed the advantages of using the ETC in parallel to the main turbine by carrying out simulations in a commercial software for engine simulation. Their suggestions improved fuel economy by $4.74 \%$ at US06 driving cycle.

A second law analysis indicates more detailed information on availability losses associated with different components and phenomena related to engines [11]. Specific works focused on different waste heat recovery systems as a way to improve several engine parameters, such as fuel economy, thermal efficiency, among others [12], [13]. Within this context, an exergy-based analysis was used to carry out investigations on data experimentally obtained from the turbocharging system of a downsized spark-ignition engine in development. Parameters such as engine power, mass and exergy flow rates, thermal efficiency and wastegate flow rate were obtained for allimportant cases related with the engine operation range. After evaluating the performance of the system, an ETC is virtually added by assuming that its components have a similar behavior of those from the real system. 


\begin{tabular}{|c|c|c|c|c|c|c|c|c|c|c|c|c|c|c|c|c|c|c|c|c|c|c|c|}
\hline \multicolumn{24}{|c|}{ Experimental studied case filtering } \\
\hline \multirow{2}{*}{$\begin{array}{c}\text { Engine } \\
\text { Load }\end{array}$} & \multicolumn{23}{|c|}{ Engine Speed (RPM) } \\
\hline & 1000 & 1250 & 1500 & 1750 & 2000 & 225 & & 2500 & 2750 & 3000 & 32 & & 500 & 3750 & 4000 & 4250 & 4500 & 4750 & 5000 & 5250 & 5500 & 5750 & 6000 \\
\hline \multicolumn{24}{|c|}{\begin{tabular}{|l|l|} 
Full Load \\
\end{tabular}} \\
\hline \multicolumn{24}{|l|}{24 bar } \\
\hline \multirow{2}{*}{\multicolumn{24}{|c|}{$\frac{22 \text { bar }}{20 \text { bar }}$}} \\
\hline & & & & & & & & & & & & & & & & & & & & & & & \\
\hline \multicolumn{24}{|l|}{18 bar } \\
\hline \multirow{2}{*}{\multicolumn{24}{|c|}{16 bar }} \\
\hline \multirow{2}{*}{\multicolumn{24}{|c|}{$\begin{array}{l}14 \text { bar } \\
12 \text { bar }\end{array}$}} \\
\hline \multirow{2}{*}{\multicolumn{24}{|c|}{$\frac{12 \text { bar }}{10 \text { bar }}$}} \\
\hline & & & & & & & & & & & & & & & & & & & & & & & \\
\hline \multicolumn{24}{|l|}{8 bar } \\
\hline \multicolumn{24}{|l|}{6 bar } \\
\hline \multicolumn{24}{|l|}{4 bar } \\
\hline 2 bar & & & & & & & & & & & & & & & & & & & & & & & \\
\hline
\end{tabular}

The simulated ETC system consists of a turbine attached downstream of wastegate valve of the main turbine. With this addition, the exhaust exergy would always be partially recovered, in higher charges by the main turbine to power the compressor and in lower charges by the free turbine to generate electricity. Performance parameters were then re-calculated for the new proposed system indicating the advantages of implementing the ETC system as a form of recovering energy to the electric system of a hybrid vehicle equipped with a downsized engine.

\section{Materials and Methods \\ 2.1 Experimental Setup}

Data was obtained from bench tests performed on a downsized, 3-cylinder in-line turbocharged spark-ignition engine with direct fuel injection. Its maximum power is in the magnitude order of $90 \mathrm{~kW}$. At the moment this engine is at development for commercial applications, therefore the authors cannot provide detailed engine characteristics. Gasohol E10 was used as fuel. The engine was operating under normal conditions, i.e., the electronic control unit (ECU) automatically controlled spark timing and air-fuel ratio. Pressure and temperature were measured in the following locations: compressor upstream and downstream, turbine upstream and downstream.

The bench tests involved 273 different cases, which intend to measure the influence of engine speed (from 1000 to 6000 RPM) and load (from 2 bar BMEP to full load conditions for each engine speed) on the performance of the turbocharged engine. Some specific cases had problems on recording the data. Hence, they were not used on this study.

The experiment measurements also involved air and fuel flow rates, brake torque and the environment conditions (temperature, pressure and relative humidity).

\subsection{Selection of the Studied Tests}

From all 273 experiments our research group developed, 229 were measured. Still, this did not mean that all these cases were applicable to our study. Thus, the laboratory group decided to select the cases whose measurements indicated that the turbocharger was on operational state, as detailed below.

In order to analyze rigorously the measurements, turbocompressor maps are very useful. Since the group did not have access to proper charts for the turbocharging system of the tested engine, the authors decided to apply a specific criterion to select representative cases, which was based on real operation of the turbocompressor. At very low expansion and/or compression ratios, this device was not properly operational. Hence, the group chose the cases where the turbocharging system exerts an influence on the engine operation conditions. The selection criterion was that both expansion and compression ratios from the turbine and compressor should be higher than 1.2, respectively.

Additionally, a second criterion was applied, in order to eliminate the cases which showed high uncertainties regarding upstream and downstream turbine temperature measurements, which implied in inconsistent results. After both criteria, the group obtained the representative cases. Table 1 shows all studied cases, with colors indicating what happened to all these measurements. First, the red color highlights that some problems happened with data recording, just as previously commented on the Experimental setup section. The orange color indicates the cases where both expansion and compression ratios are lower than 1.2 (first selection). The second selection is indicated by the gray color, whose cases presented inconsistent results, hence the group chose to discard those cases. Finally, the green color represents all representative cases, whose data are physically consistent with engine operation conditions. Then, the authors applied the exergybased analysis.

Based on detailed criteria, we have narrowed down from 229 to 142 acceptable cases. As can be noticed, Table 1 indicates indirectly a regular engine torque curve (by ignoring the full load line), increasing with higher speeds until it reaches a maximum near 3000 RPM and then it starts decreasing at higher values. The selected tests involved full and partial load conditions and their operational conditions are summarized in Table 2.

\section{Table 2. List of performed tests and their operational} conditions.

\begin{tabular}{lll}
\hline & Partial load & Full load \\
\hline Air-fuel ratio & Stoichiometric & Rich \\
Engine speed, rpm & 1500 to 6000 & 1500 to 6000 \\
$\begin{array}{l}\text { Compression ratio for } \\
\text { compressor }\end{array}$ & 1.2 to 1.6 & 1.2 to 2.6 \\
Expansion ratio for turbine & 1.2 to 1.8 & 1.2 to 2.4 \\
\hline
\end{tabular}

The engine turbocompressor dimensions are indicated in Table 3.

Table 3. Engine turbocompressor dimensions.

\begin{tabular}{lll}
\hline & Compressor & Turbine \\
\hline Inlet diameter $(\mathrm{m})$ & 0.034 & 0.050 \\
Outlet diameter $(\mathrm{m})$ & 0.041 & 0.071 \\
\hline
\end{tabular}




\subsection{Assumptions of the Model}

After the experimental procedure and selection of most representative results, the group applied the concepts of first and second laws of thermodynamics to study a system model, which contains a turbocharged direct injection spark-ignition engine, its turbocharger, and a wastegate valve associated with the turbocharging system. The main purpose of this study is to analyze the viability of combining the turbocharging system with vehicle hybridization. The chosen way to reach this objective is to apply a second law analysis on the experimental measurements, in order to understand the exergy utilization through this open system and therefore realize some opportunities of exergy efficiency enhancement. Another objective is then to evaluate the benefits and drawbacks of the implementation of an additional turbine (ETC) in the main system, which will receive the exhaust excess mass flow rate instead of wastegate valve, thus amplifying the power provided by the main system. This additional power would feed the electric system of a hybrid vehicle equipped with this studied engine.

The authors developed a thermodynamic model to be applied on this study considering the aforementioned objectives. Some assumptions were required in order to make proper statements about this model. Those assumptions are described below:

1. The experimental measurements were made during steady-state conditions;

2. The air/gas pressure losses through the tubes are considered negligible;

3. Both air and combustion gases are treated as ideal gases;

4. The dry air molar composition [14] upstream and downstream compressor is: $\mathrm{N}_{2}: 78.084 \%, \mathrm{O}_{2}$ : $20.946 \%, \mathrm{Ar}: 0.937 \%$ and $\mathrm{CO}_{2}: 0.033 \%$;

5. The composition of combustion gases downstream the engine may be assumed as the one obtained from a simplified global combustion reaction of the fuel E10 and moist air, which its relative humidity for each case was measured during the experiments;

6. The thermodynamic properties used in the model (enthalpy, entropy, free Gibbs energy) are obtained based on JANAF thermodynamic tables [15];

7. The virtual turbine behaves the same way as the main turbine of the turbocharger, even though the mass flow rates (and consequently the efficiencies) are different;

8. The compressor, the engine and the turbine are all considered to be adiabatic. Also, the work produced by the turbine is integrally transferred to the compressor through the shaft, i.e., the mechanical efficiency is assumed $100 \%$;

9. The chemical exergy of E10 was calculated based on the values for Gasoline $\left(E_{C h}^{f}=4784051 \frac{\mathrm{kJ}}{\mathrm{kmol}}\right)$ and Ethanol $\left(E_{C h}^{f}=1361884 \frac{\mathrm{kJ}}{\mathrm{kmol}}\right)$;

10. Ambient conditions at the test location were assumed as reference conditions for the second law analysis, i.e., reference pressure and temperature were measured during the development of experimental cases.
Figure 1 presents the flowchart of our study. The simplified combustion analysis involves the main ideas presented in [16]. The turbocharger analysis involves both compressor and the main turbine analysis.

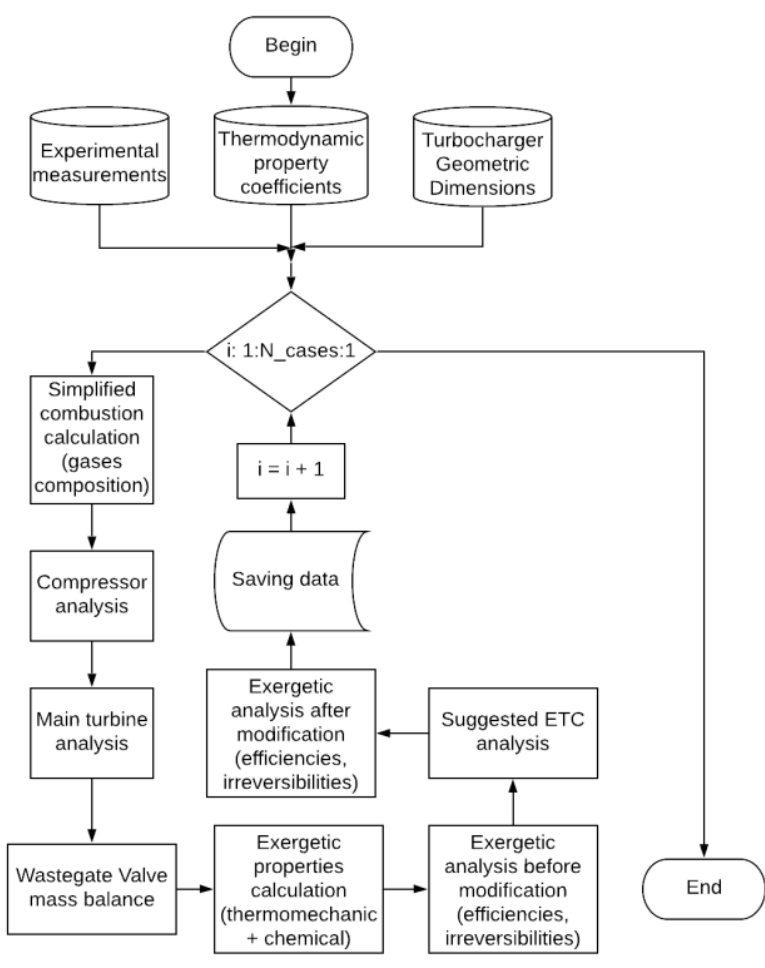

Figure 1. Flowchart of the analysis.

\subsection{Turbocharger Analysis}

The mass flow through the compressor is composed by the air intake $\dot{m}_{a}=\dot{m}_{C}$, since fuel is directly injected in the combustion chamber. Also, since blow-by effects are being ignored, the exhaust mass flow is equal to the air added to the fuel flow, as represented in Eq. (1).

$\dot{m}_{a}+\dot{m}_{f}=\dot{m}_{g}$

The exhaust flow is divided between the turbine and the wastegate, as demonstrated in Eq. (2).

$\dot{m}_{g}=\dot{m}_{T}+\dot{m}_{W G}$

The power consumed by the compressor can be calculated by applying the 1st law of thermodynamics, resulting in Eq. (3). Thermodynamic properties are given as function of the temperature. Both intake and exhaust gases are assumed to behave as ideal gases.

$\dot{W}_{C}=\dot{m}_{C}\left(h_{U, C}-h_{D, C}+\frac{V_{U, C}^{2}}{2}-\frac{V_{D, C}^{2}}{2}\right)$

Flow velocity cannot be neglected. It can be calculated by Eq. (4) as function of the measured properties.

$V=\frac{\dot{m}\left(\frac{\bar{R}}{M}\right) T}{P A}$

An isentropic (or first law) efficiency for the compressor is derived in Eq. (5), by dividing the power consumed by the compressor at ideal conditions $\left(\dot{W}_{C, s}\right)$, i.e., through an isentropic compression, and the real power consumed by the compressor. An isentropic compression is determined in Eq. (6) by integrating the fundamental 
relation providing the entropy at downstream of the compressor.

$$
\begin{aligned}
& \eta_{C}=\frac{\dot{W}_{C, s}}{\dot{W}_{C}} \\
& \Delta s=s^{o}\left(T_{D, s}\right)-s^{o}\left(T_{U}\right)-\frac{\bar{R}}{M} \ln \left(\frac{P_{D}}{P_{U}}\right)=0
\end{aligned}
$$

The specific work developed by the turbine is calculated by Eq. (7). Turbine mass flow is calculated in Eq. (8) by assuming negligible mechanical losses in the coupling between compressor and turbine.

$$
\begin{aligned}
& w_{T}=h_{U, T}-h_{D, T}+\frac{V_{U, T}^{2}}{2}-\frac{V_{D, T}^{2}}{2} \\
& \dot{m}_{T}=-\frac{\dot{W}_{C}}{w_{T}}
\end{aligned}
$$

The isentropic efficiency of the turbine is derived in Eq. (9) from the ratio between the real power developed by the turbine and the power developed in the ideal case.

$$
\eta_{T}=\frac{\dot{W}_{T}}{\dot{W}_{T, s}}
$$

\subsection{Electric Turbo Compound Implementation}

The effects of implementing an ETC system by adding a free turbine to recover exergy lost in the wastegate valve is evaluated. A scheme of the proposed system is illustrated in Figure 2. The system is virtually implemented using algorithms implemented in MatLab®.

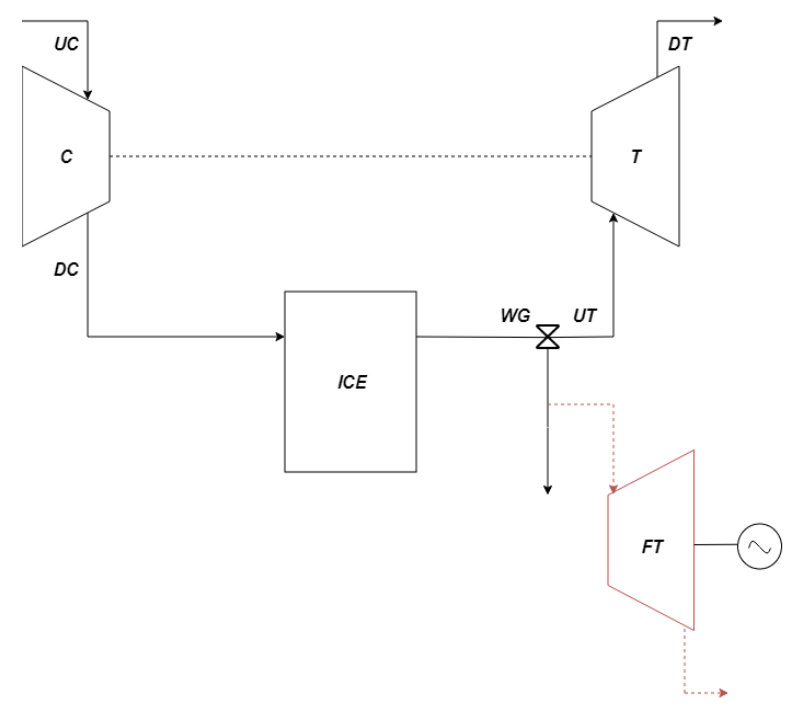

Figure 2. Scheme of the proposed system.

It is assumed that the wastegaste flow in the original system would be directed to the free turbine, leading to $\dot{m}_{F T}=\dot{m}_{W G}$. The power recovered by the free turbine is estimated in Eq. (10), by assuming that the free turbine works at the same conditions of the main turbine.

$\dot{W}_{F T}=\dot{m}_{F T}\left(h_{U, T}-h_{D, T}+\frac{V_{U, T}^{2}}{2}-\frac{V_{D, T}^{2}}{2}\right)$

The second law or exergetic efficiencies for the compressor and both turbines are presented in Eqs. (11)(13):

$\eta_{C}^{2 n d}=\frac{\dot{m}_{C}\left(e_{D, C}^{f}-e_{U, C}^{f}\right)}{\dot{W}_{C}}$
$\eta_{T}^{2 n d}=\frac{\dot{W}_{T}}{\dot{m}_{T}\left(e_{U, T}^{f}-e_{D, T}^{f}\right)}$

An exergetic efficiency is derived for the original turbo-compressor system in Eq. (13), by considering the reduction of exergy flow in the turbine as input and the gain of exergy flow in the compressor as output. Exergy flow defined by Eq. (14).

$\eta_{T C}^{2 n d}=\frac{\dot{m}_{C}\left(e_{D, C}^{f}-e_{U, C}^{f}\right)}{\dot{m}_{T}\left(e_{U, T}^{f}-e_{D, T}^{f}\right)}$

$e^{f}=h-h_{0}-T_{0}\left(s-s_{0}\right)+\frac{V^{2}}{2}$

The global exergetic efficiency for the engine is defined in Eq. (15) by considering the power developed by it as output and the chemical exergy of the fuel as exergetic input.

$\eta_{G}^{2 n d}=\frac{\dot{W}_{\text {engine }}}{\dot{m}_{f} e_{C h}^{f}}$

The desired output of the free turbine is the power recovered while the exergetic input is the flow that is discharged through the wastegate valve in the original system. Therefore, an exergetic efficiency is calculated for the new turbine by Eq. (16).

$\eta_{F T}^{2 n d}=\frac{\dot{W}_{F T}}{\dot{m}_{F T}\left(e_{D, T}^{f}-e_{U, T}^{f}\right)}$

A new definition for exergetic efficiency for the turbocharging system is derived after applying the proposed modifications in Eq. (17). It is assumed that the new outputs of the turbo-compressor system are both the gain in exergy of the flow in the compressor and the recovered power from the free turbine. The new exergetic efficiency for the engine system is presented in Eq. (18). It considers as desired outputs both the brake power and the recovered power in the free turbine, while the input remains the fuel chemical exergy.

$$
\begin{aligned}
\eta_{T C^{\prime}}^{2 n d} & =\frac{\dot{m}_{C}\left(e_{D, C}^{f}-e_{U, C}^{f}\right)+\dot{W}_{F T}}{\dot{m}_{g}\left(e_{U, T}^{f}-e_{D, T}^{f}\right)} \\
\eta_{G^{\prime}}^{2 n d} & =\frac{\dot{W}_{\text {engine }}+\dot{W}_{F T}}{\dot{m}_{f} e_{C h}^{f}}
\end{aligned}
$$

The amount of exergy available downstream before and after the modification are presented by Eqs. (19)-(20):

$$
\begin{aligned}
& \dot{E}_{\text {exhaust }}=\dot{m}_{T} e_{D, T}^{f}+\dot{m}_{W G} e_{U, T}^{f} \\
& \dot{E}_{\text {exhaust }^{\prime}}=\dot{m}_{g} e_{D, T}^{f}
\end{aligned}
$$

\section{Results \\ 3.1 Wastegate Analysis}

The first analysis focused on the wastegate (WG) valve, since the modifications we suggested to apply on the system involves directly its mass flow rate at different loads and speeds.

Relative wastegate mass flow rate (ratio of wastegate mass flow rate with exhaust engine mass flow rate) as function of engine speed is shown in Figure 3. At 12 Bar BMEP (partial load), the mass flow rate fluctuates between 23 and $33 \%$, even though it remains relatively stable for most engine speeds. Although a nearly constant percentage of wastegate is observed for full load conditions, the flow 
through wastegate is actually being increased, as it is noted in Figure 4, for partial and full load cases. We can also notice that we have a direct relationship between absolute wastegate flow rate and engine speed.

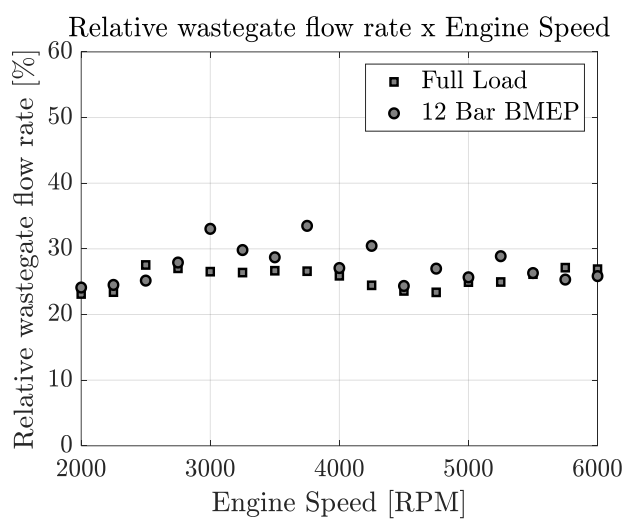

Figure 3. Relative wastegate flow rate as function of engine speed for full and partial loads

Additionally, it is verified a relationship between waste gate flow rate and pressure by comparing Figs. 4, 5 and 6 for both partial and full load conditions. A limit for pressure is observed for full load cases, where this limit pressure reaches nearly 3.6 bar. The turbine is designed in order to not exceed this limit for structural reasons, thus this value is considered the upper limit reference value for the turbine operation. It is also noted that this limit is not achieved for partial load conditions, as expected.

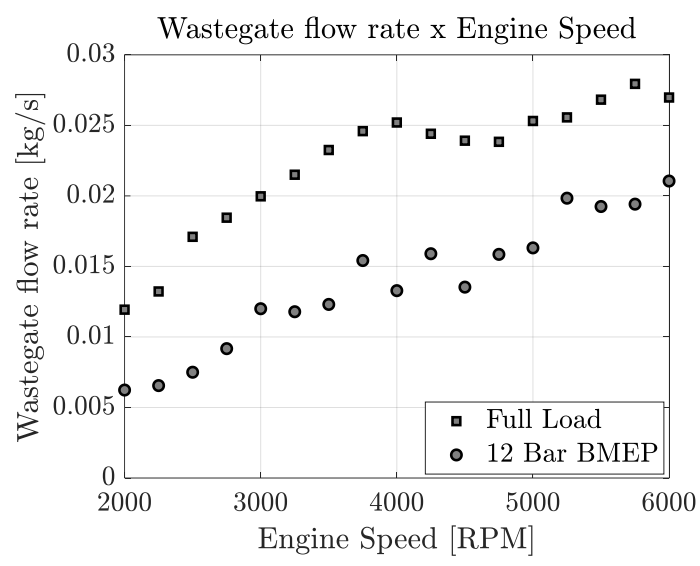

Figure 4. Absolute wastegate flow rate as function of engine speed for full and partial loads.

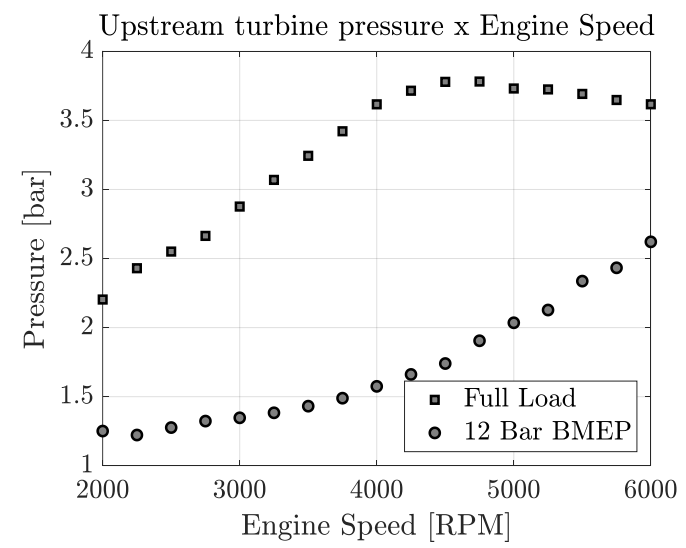

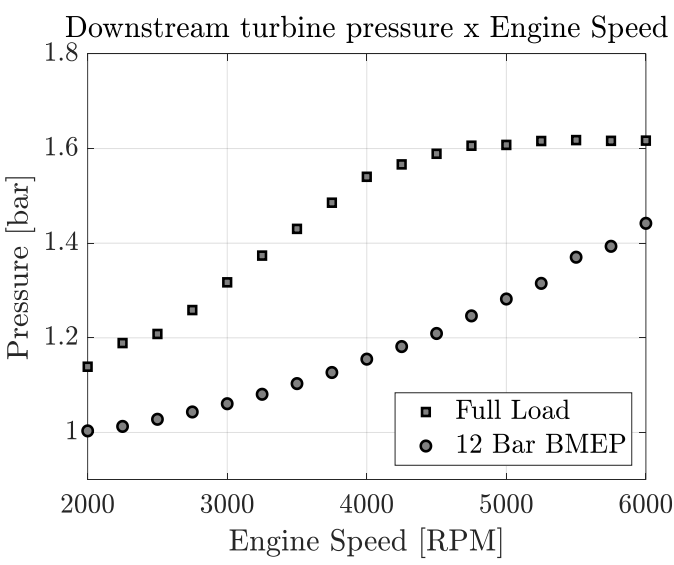

Figure 6. Turbine downstream pressure.

The wastegate analysis also presents a relationship between relative wastegate flow rate and engine load, which is shown in Figure 7 for 2000, 4000 and 6000 RPM. It seems that the load is inversely proportional to relative WG flow rate. This flow rate is higher at the lowest BMEPs (4 bar for 6000 RPM, 6 bar for 4000 RPM and 12 bar for 2000 RPM).

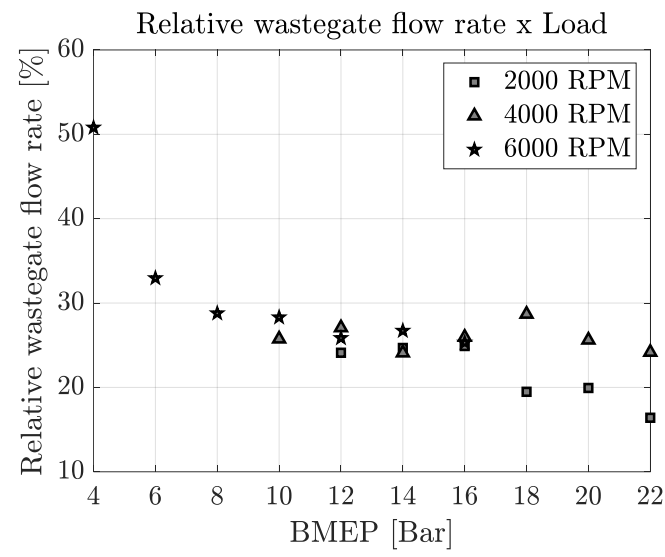

Figure 7. Wastegate flow as function of engine load.

Indeed, all these results highlight that an opportunity for waste heat recovery is available in automobiles for both partial and full load conditions. Turbine exergetic efficiency and upstream pressure indicate that there is a potential exergy source available on the wastegate flow. Additionally, the wastegate mass flow rate is significant (at least $22 \%$, Figure 7). Figure 8 represents this idea more clearly, where the wastegate exergy map is presented as function of engine speed and load. For most cases, there is plenty of wasted exergy (nearly $15 \mathrm{~kW}$ ) related with wastegate valve, especially at engine speeds higher than 3000 RPM. Since the turbocompressor is operational at BMEPs higher than 12 bar, most conditions present opportunities of additional exergy usage. The empty regions in the figure indicate the cases where the engine is not operational. Hence, this amount of exergy is available and justifies a virtual simulation of an ETC system, whose analysis follows on the next section.

Figure 5. Turbine upstream pressure. 


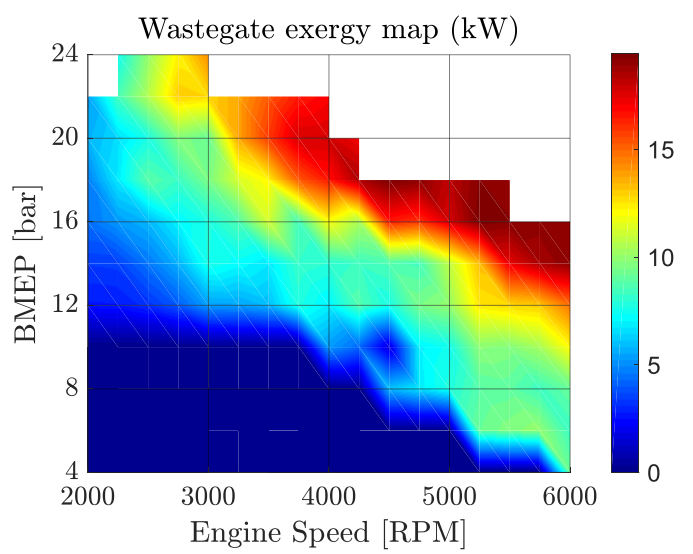

Figure 8. Wastegate exergy map as function of engine load and speed.

\subsection{Electric Turbo Compound Analysis}

We applied a thermodynamic model to investigate possible benefits and drawbacks of replacing the wastegate valve by an additional turbine. The mass flow ratios applied in this analysis were the same as real values from wastegate measurements. Studied parameters were calculated before and after the implementation of the ETC system. These parameters are compressor and turbine efficiencies, free turbine power, exergetic free turbine efficiency and both turbocompressor and global (engine + turbocompressor + free turbine) exergetic efficiencies. Figs. 9 to 14 show those results for partial load (12 bar BMEP) and full load conditions as functions of engine speed.

First, the isentropic and exergetic efficiencies based on experimental measurements for both compressor and turbine are presented in Figs. 9 and 10, respectively. Both isentropic and exergetic efficiencies present the same trends in both figures, with exergetic efficiency higher than isentropic. Compressor presents an optimum operation at the engine speed of $3500 \mathrm{rpm}$ for full load (isentropic $70 \%$ and exergetic $79 \%$ ) while its less efficient operation point is found at this speed range for the presented partial load condition (57\% and 60\%, respectively). The turbine presents a continuous decrease for both load conditions, with its peak value near low speeds (2000 RPM).

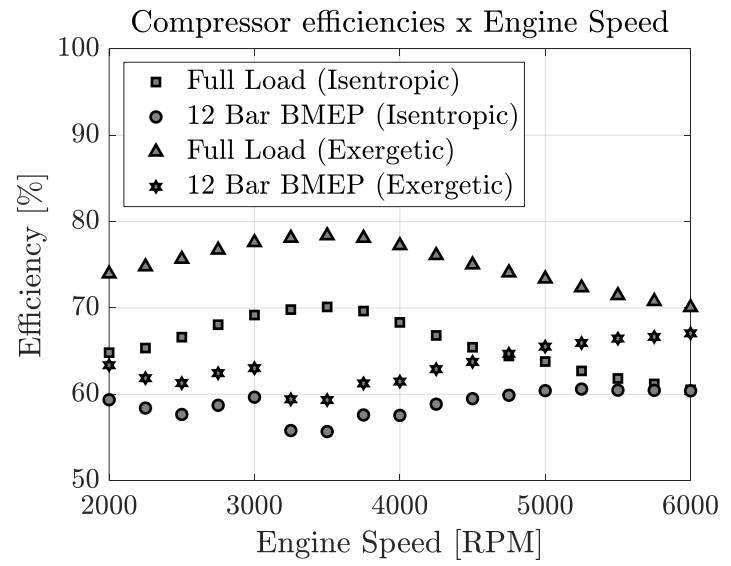

Figure 9. Compressor first and second law calculated by Equations (5) and (11), respectively.

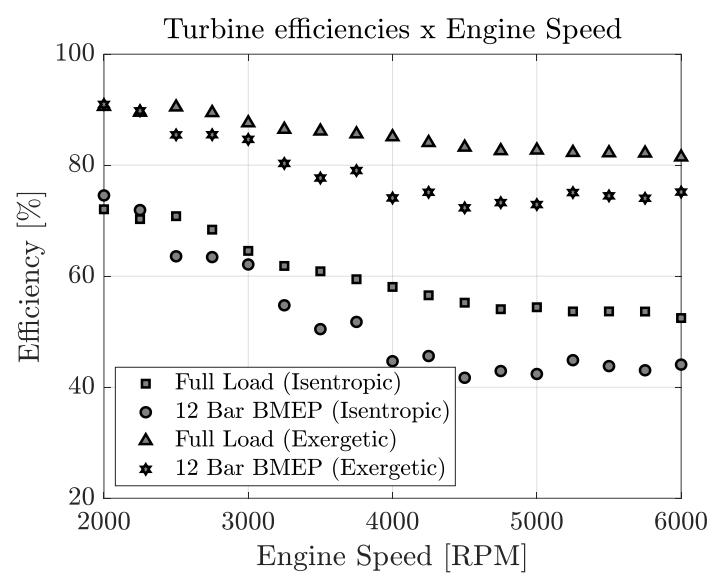

Figure 10. Main turbine first and second law efficiencies calculated by Equations (9) and (12), respectively.

The global (or engine system) exergetic efficiency results are presented in Figure 11. Before the virtual turbine implementation, full load conditions present efficiencies varying between 20 and $27 \%$, which are similar to expected from a regular first law efficiency in common sparkignition engines. Furthermore, the rich air-fuel ratio conditions required from engines to operate at full load collaborates for lower efficiencies, which is clear when those values are compared to efficiencies at partial load conditions. At partial load, it is noticeable that the exergetic efficiency go up to $30 \%$ for most cases. Another important information regarding Figure 11 is the efficiency improvement after the ETC implementation. At full load conditions, the global efficiency raises more than $2 \%$ for most engine speeds, while at partial load it varies near $1 \%$ improvement. Thus, the power recovering leads to an increase in exergetic efficiency for all conditions.

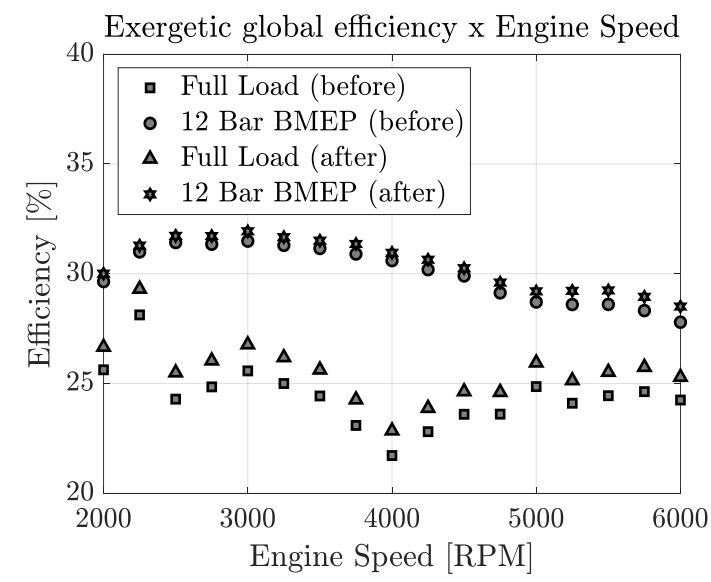

Figure 11. Engine system exergetic efficiency calculated before (Eq. (15)) and after (Eq. (18)) the ETC implementation.

The power recovered by the free turbine is presented in Figure 12. Recovered power is clearly dependent on turbine flow for partial loads. However, the maximum power can be achieved only when engine speed is greater than 4000 RPM for full load conditions. This result indicates that the power recovered is directly proportional to wastegate flow rate (see Figure 4). The level of power recovered at partial load conditions $(0.2$ to $1.9 \mathrm{~kW})$ is comparable to that of convenience outlet (Level 1 type) while the power 
recovered at full load conditions (from 1.9 to $4.0 \mathrm{~kW}$ ) is comparable to semifast recharging stations (Level 2 type) [17]. This amount of turbine power needs to be converted into electric power, which requires an evaluation of the energetic conversion efficiency.

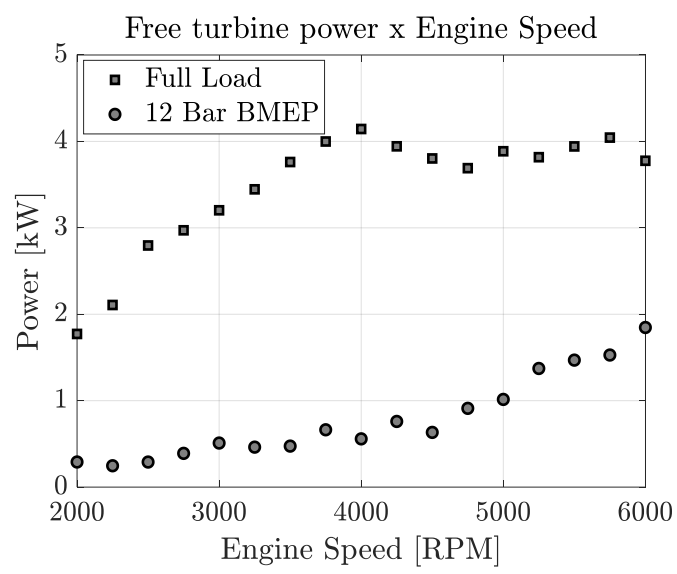

Figure 12. Free turbine developed power calculated by Eq. (10).

The relationship between exergetic efficiency of the free turbine with engine speed is presented in Figure 13. At full load conditions, this efficiency decreases from 90 to $80 \%$, even though the free turbine power increases at higher engine speeds. This efficiency drop is balanced by higher wastegate flow rate (Figure 4), especially at 4000 RPM. Meanwhile, at partial load conditions the efficiency decreases from 90 to $75 \%$.

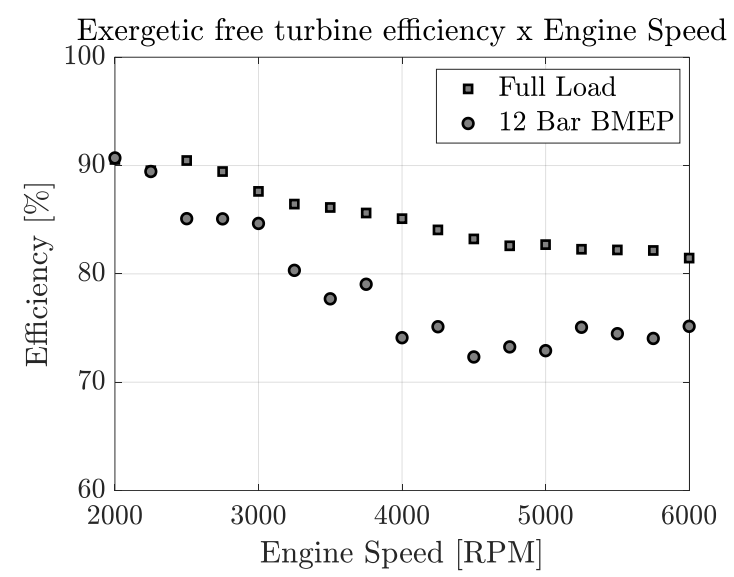

Figure 13. Exergetic free turbine efficiency calculated by Eq. (16).

Exergetic efficiency for the turbocompressor system is presented in Figure 14. The exergetic efficiency calculated before the virtual implementation of the free turbine in the system consists of the product between compressor exergetic efficiency (Figure 9) and turbine exergetic efficiency (Figure 10). After the free turbine implementation, the exergetic efficiency depends also on the power recovered by the free turbine. An increase in exergetic efficiency for the turbocompressor system can be verified for all operational conditions. For partial load conditions, the gain overcomes $6 \%$, reaching almost $10 \%$ in some cases, while at full load it stays near $4 \%$.

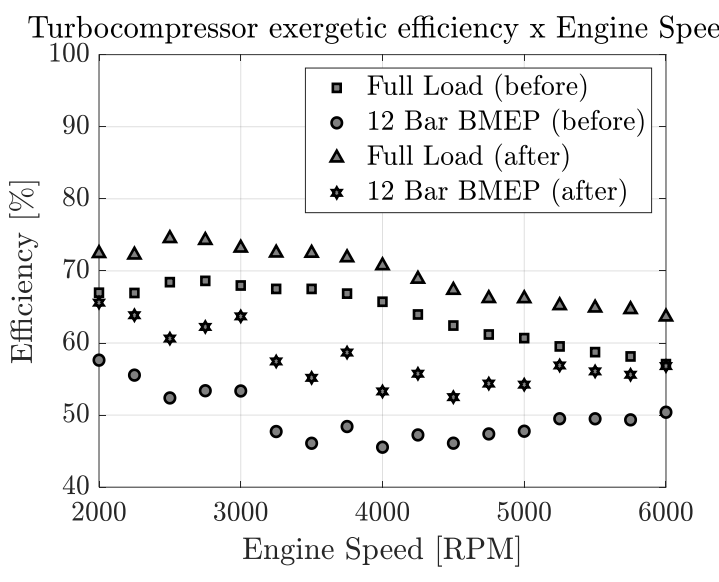

Figure 14. Turbocompressor exergetic efficiency calculated before (Eq. (13)) and after (Eq. (17)) the ETC implementation.

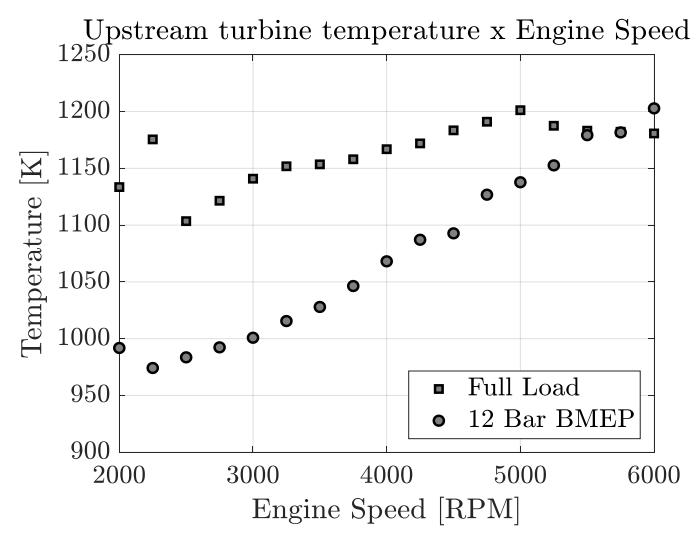

Figure 15. Turbine upstream temperature.

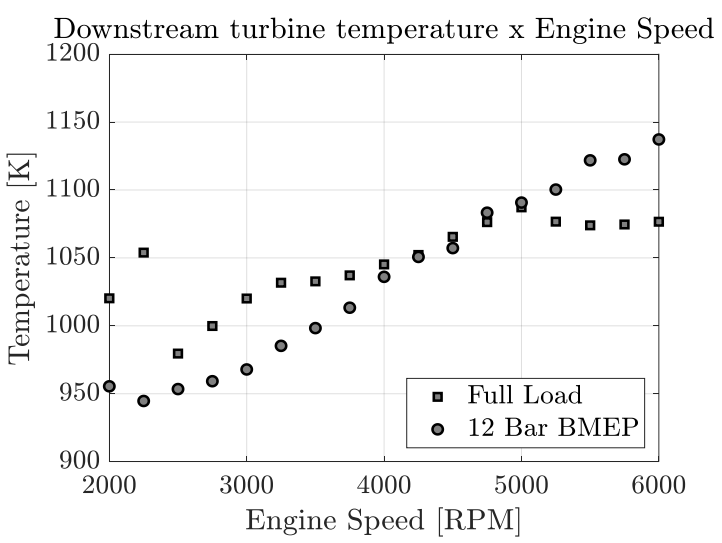

Figure 16. Turbine downstream temperature.

The temperature of exhaust gases upstream and downstream of both turbines are presented in Figs. 15 and 16 respectively. It is observed that the turbine downstream exhaust gas temperatures are between $950 \mathrm{~K}$ and $1150 \mathrm{~K}$ for both partial and full load conditions. Consequently, there is still a considerable amount of available exergy contained in the exhaust gases (with available pressure to further expansion, Figure 6), even though these losses are reduced after the implementation of the free turbine. Thus, this situation indicates the possibility of combining the ETC technology with other forms of recovering energy. 


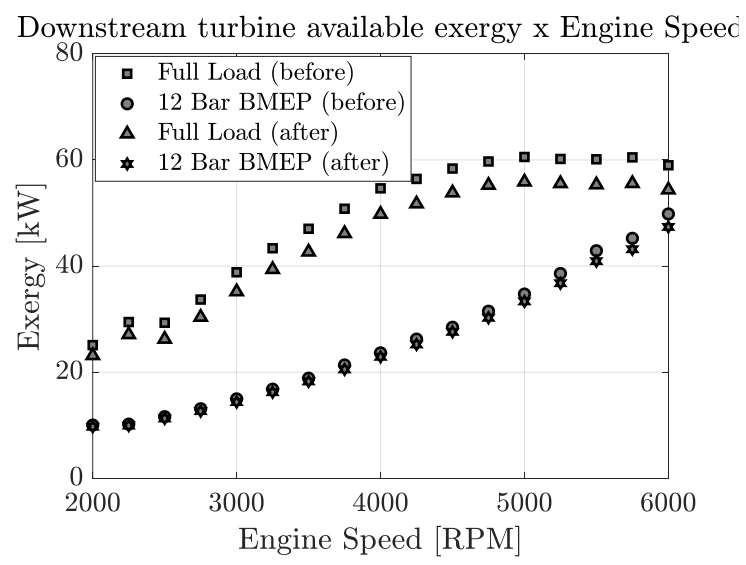

Figure 17. Exergy losses through the exhaust system calculated before (Eq. (19)) and after (Eq. (20)) the ETC implementation.

In order to corroborate this final analysis, the downstream turbine available exergy is presented in Figure 17. The reduction is higher for full load conditions, as expected (approximately $4 \mathrm{~kW}$ at the best scenario), while at partial load there is a slightly reduction of available exergy ( 1 to $2 \%$ relative).

\section{Conclusions}

Experimental data was used to perform an exergetic analysis on the turbocharging system of a spark-ignition engine fueled with gasohol E10. Results were used to estimate the implementation of an ETC system thereafter by assuming that a free turbine would recover the energy from the flow that would be discharged from the wastegate valve in the original system.

The viability of engine turbocharging with vehicle hybridization is confirmed based on parameters generated by an exergetic analysis with interesting benefits. A clear advantage of a free turbine implementation is that the system efficiency increases at all operational conditions (gain of 1 to $2 \%$ ); even though a possible drawback is that the highest increases occur only at full load conditions. The amount of energy that can be recovered by the free turbine varies between 0.2 to $1.9 \mathrm{~kW}$ for partial load (comparable to convenience outlets) and it can reach up to $4 \mathrm{~kW}$ at full load conditions (comparable to semifast recharging stations). Comparing these power values with actual engine parameters, the turbine can recover up to $1.2 \%$ of total fuel exergy (E10) and is equivalent to $5.2 \%$ of actual engine power at full load conditions.

Additionally, the second law analysis presented some extra opportunities of exergetic efficiency enhancement, as there is still considerable amount of available exergy in the exhaust gases (up to $60 \mathrm{~kW}$ ) even after the implementation of a free turbine. The engine exergetic efficiency increased up to $2 \%$ at full load conditions, while for partial loads it raised around $1 \%$. Those results indicate the possibility of combining this technology with other forms of energy recovering, such as waste heat recovering or low pressure turbo compounding, which may enhance even more the global efficiency.

The main hypothesis related with this presented analysis is that the free turbine operates at similar conditions to those of the main turbine. Thus, a future work comprises an expanded analysis including the use of a turbine map, since main and free turbines operate with different mass flow rates, possibly leading to different operational conditions for each turbine. Moreover, an analysis involving the driving cycles conditions can be performed, indicating the advantages of the ETC focusing on urban and highway application, providing values for fuel consumption and emission levels reduction.

\section{Acknowledgements}

The authors would like to express their gratitude to prof. Clayton Barcelos Zabeu and the staff of Mauá Institute of Technology for the execution of the experimental tests and to Fundação de Amparo à Pesquisa do Estado de São Paulo (FAPESP) for the financial support through process No. 2013/50238-3 and 2018/18859-1.

\section{Nomenclature}

$A$ - Area, $m^{2}$

$e^{C h}$ - Intensive chemical exergy $(\mathrm{J} / \mathrm{kg})$

$e^{f}$ - Intensive flow exergy $(\mathrm{J} / \mathrm{kg})$

$\dot{E}$ - Extensive exergy rate $(W)$

$h$ - Intensive enthalpy $(\mathrm{J} / \mathrm{kg})$

$\dot{m}$ - Mass flow $(\mathrm{kg} / \mathrm{s})$

$M$ - Molecular weight $(\mathrm{kg} / \mathrm{kmol})$

$P$ - Absolute pressure $(\mathrm{Pa})$

$\bar{R}$ - Universal gas constant $(J /(m o l . K))$

$s$ - Intensive entropy $(J /(k g . K))$

$s^{\circ}$ - Intensive entropy at reference pressure $(J /(\mathrm{kg} . \mathrm{K}))$

$T$ - Temperature $(K)$

$V$ - Velocity $(\mathrm{m} / \mathrm{s})$

$\dot{W}$ - Power $(W)$

$s$ - Intensive entropy $(J /(k g . K))$

$\dot{w}$ - Specific work $(\mathrm{J} / \mathrm{kg})$

\section{Greek Symbols}

$\eta$ - Isentropic efficiency

$\eta^{2 n d}$ - Second law efficiency

\section{Subscripts and superscripts}

a - Air

C - Compressor

$D$ - Downstream

engine - Engine

exhaust - Exhaust

exhaust ' - Exhaust modified

${ }_{F T}$ - Free turbine

$f$ - Fuel

${ }_{G}$ - Global

$G^{\prime \prime}$ - Global modified

$T$ - Turbine

$T_{C}$ - Turbocompressor system

$T C^{n}$ - Turbocompressor system modified

$U$ - Upstream

${ }_{W G}$ - Wastegate valve

${ }_{0}$ - Reference conditions 


\section{References}

[1] C. C. Chan, "The State of the Art of Electric, Hybrid, and Fuel Cell Vehicles," Proc. IEEE, vol. 95, no. 4, pp. 704-718, 2007.

[2] R. El Chammas and D. Clodic, "Combined Cycle for Hybrid Vehicles," in SAE paper, 2005.

[3] X. Zhang, K. T. Chau, and C. C. Chan, "Overview of Thermoelectric Generation for Hybrid Vehicles," $J$. Asian Electr. Veh., vol. 6, no. 2, pp. 1119-1124, 2008.

[4] G. Canbolat and H. Yaşar, "Performance Comparison for Series and Parallel Modes of a Hybrid Electric Vehicle," Sak. Univ. J. Sci., vol. 23, no. 1, pp. 1-1, 2019.

[5] A. Gabriel-Buenaventura and B. Azzopardi, "Energy recovery systems for retrofitting in internal combustion engine vehicles: A review of techniques," Renew. Sustain. Energy Rev., vol. 41, pp. 955-964, 2015.

[6] J. Fu et al., "A comparative study on various turbocharging approaches based on IC engine exhaust gas energy recovery," Appl. Energy, vol. 113, pp. 248257, 2014.

[7] U. Hopmann and M. C. Algrain, "Diesel Engine Electric Turbo Compound Technology," in SAE Technical Papers, 2003.

[8] F. Ortenzi, A. Genovese, M. Carrazza, F. Rispoli, and P. Venturini, "Exhaust Energy Recovery with Variable Geometry Turbine to Reduce Fuel Consumption for Microcars," in SAE Technical Papers, 2018, vol. 2018Septe.

[9] A. M. . Bin Mamat, R. F. Martinez-Botas, M. C. Chiong, S. Rajoo, S. Petrovic, and A. Romagnoli, "Exhaust Gas Energy Recovery Via Electric Turbocompounding," Energy Procedia, vol. 75, pp. 1555-1559, 2015.
[10] W. Zhuge, L. Huang, W. Wei, Y. Zhang, and Y. He, "Optimization of an Electric Turbo Compounding System for Gasoline Engine Exhaust Energy Recovery," in SAE Technical Papers, 2011.

[11] C. D. Rakopoulos and E. G. Giakoumis, "Second-law analyses applied to internal combustion engines operation," Prog. Energy Combust. Sci., vol. 32, no. 1, pp. 2-47, 2006.

[12]H. Aghaali and H.-E. Ångström, "A review of turbocompounding as a waste heat recovery system for internal combustion engines," Renew. Sustain. Energy Rev., vol. 49, pp. 813-824, 2015.

[13] W. M. S. R. Weerasinghe, R. K. Stobart, and S. M. Hounsham, "Thermal efficiency improvement in high output diesel engines a comparison of a Rankine cycle with turbo-compounding," Appl. Therm. Eng., vol. 30, no. 14-15, pp. 2253-2256, 2010.

[14]R. J. B. Way, "Methods for Determination of Composition and Thermodynamic Properties of Combustion Products for Internal Combustion Engine Calculations," Proc. Inst. Mech. Eng., vol. 190, no. 1, pp. 687-697, 1976.

[15] J. Malcolm W. Chase, "NIST-JANAF Thermochemical Tables," Am. Chem. Soc. Am. Inst. Phys. Natl. Inst. Stand. Technol., 1998.

[16]C. R. Ferguson and A. T. Kickpatrick, Internal Combustion Engines - Applied Thermosciences, 2nd ed. John Wiley and Sons, 2001.

[17] M. Yilmaz and P. T. Krein, "Review of Battery Charger Topologies, Charging Power Levels, and Infrastructure for Plug-In Electric and Hybrid Vehicles," IEEE Trans. Power Electron., vol. 28, no. 5, pp. 2151-2169, 2013. 